\title{
Thermal study of an indium trisguanidinate as a possible indium nitride precursor
}

Sydney C. Buttera, Karl Ronnby, Henrik Pedersen, Lars Ojamäe and Sean T. Barry

The self-archived postprint version of this journal article is available at Linköping University Institutional Repository (DiVA):

http:/ / urn.kb.se/ resolve?urn=urn:nbn:se:liu:diva-144248

N.B.: When citing this work, cite the original publication.

Buttera, S. C., Ronnby, K., Pedersen, H., Ojamäe, L., Barry, S. T., (2018), Thermal study of an indium trisguanidinate as a possible indium nitride precursor, J ournal of Vacuum Science \& Technology. A. Vacuum, Surfaces, and Films, 36(1), . https:// doi.org/ 10.1116/ 1.5002634

Original publication available at:

https:// doi.org/ 10.1116/ 1.5002634

Copyright: AIP Publishing

http:// www.aip.org/ 


\title{
Thermal study of an indium trisguanidinate as a possible indium nitride precursor
}

Running title: Indium trisguanidinate thermolysis

Running Authors: Buttera et al.

\author{
Sydney C.Buttera, ${ }^{1}$ Karl Rönnby, ${ }^{2}$ Henrik Pedersen, ${ }^{2}$ Lars Ojamäe, ${ }^{2}$ \\ and Seán T. Barrya),1 \\ ${ }^{1}$ Department of Chemistry, Carleton University, 1125 Colonel By Drive, Ottawa, Ontario, K1S 5B6 \\ Canada \\ ${ }^{2}$ Department of Physics, Chemistry, and Biology, Linköping University, Linkoping, SE-58183 \\ Sweden
}

a) Electronic mail: sean barry@carleton.ca

Tris-N,N,-dimethyl-N',N"- diisopropylguanidinatoindium(III) has been investigated both as a chemical vapor deposition precursor and an atomic layer deposition precursor. Although deposition was satisfactory in both cases, each report showed some anomalies in the thermal stability of this compound, warrenting further investigation, which is reported herein. The compound was found to decompose to produce diisopropylcarbodiimide both by computational modeling and solution phase NMR characterization. The decomposition was shown to have an onset at approximately 120 ${ }^{\circ} \mathrm{C}$, and had a constant rate of decomposition from $150{ }^{\circ} \mathrm{C}$ to $180{ }^{\circ} \mathrm{C}$. The ultimate decomposition product was suspected to be bisdimethylamido-N,N,-dimethyl-N',N"diisopropylguanidinato-indium(III), which appeared to be an intractable, nonvolatile polymer. 


\section{INTRODUCTION}

Indium nitride $(\mathrm{InN})$ is a small band-gap semiconductor with the largest electron saturation velocity, smallest effective electron mass and highest electron mobility among the group 13 nitrides. ${ }^{1,2,3}$ It is possible to integrate $\mathrm{InN}$ in existing high electron mobility transistors (HEMT) making InN a key material for future high frequency transistors. However, deposition of single crystalline InN films is challenging with conventional chemical vapor deposition (CVD) technology using trimethyl indium $\left(\operatorname{In}\left(\mathrm{CH}_{3}\right)_{3}\right)$ and ammonia. The $\mathrm{InN}$ film decomposes to indium metal and $\mathrm{N}_{2}$ gas even at deposition temperatures as low as $500{ }^{\circ} \mathrm{C},{ }^{4}$ setting an upper limit for the deposition; this forces the use of use $\mathrm{NH}_{3} / \mathrm{In}\left(\mathrm{CH}_{3}\right)_{3}$ ratios on the order of 100,000 due to the poor reactivity of ammonia at these low temperatures. ${ }^{5}$ An alternative approach for depositing $\mathrm{InN}$ is a time-resolved CVD technique where the poor reactivity of $\mathrm{NH}_{3}$ is overcome by allowing it to react with chemisorbed indium-containing surface moieties rather than relying on this reactivity in the (dilute) gas phase. Recent studies of $\mathrm{InN}$ deposition by atomic layer deposition (ALD) have shown that it is indeed possible to deposit InN with high crystalline quality using $\operatorname{In}\left(\mathrm{CH}_{3}\right)_{3}$ and nitrogen plasmas. ${ }^{6,7}$

For use in electronics, one of the most important aspects of the deposited InN film is low impurity levels, particularly for carbon and oxygen. It is a well-known problem in ALD that the low deposition temperatures used to maintain self-limiting behaviour can lead to carbon impurities in the few atomic percent range when metal precursors with metal-carbon bonds are used. ${ }^{8}$ A recent study on plasma ALD of InN demonstrated that very long plasma exposures (on the order of $100 \mathrm{~s}$ ) were needed to bring the carbon levels in InN films down to around 3 atomic percent. ${ }^{7}$ Great care must also be taken in the construction and operation of the ALD reactor to minimize any traces of oxygen as 
indium is more prone to form the oxide, $\operatorname{In}_{2} \mathrm{O}_{3}$, than the nitride, $\mathrm{InN}$. This is highlighted by the standard formation enthalpies $\left(\Delta \mathrm{H}_{\mathrm{f}}{ }^{\circ}\right)$ for $\operatorname{In}_{2} \mathrm{O}_{3}$ and $\operatorname{InN}\left(-925.8 \mathrm{~kJ} / \mathrm{mol}^{9}\right.$ and -36.3 $\mathrm{kJ} / \mathrm{mol}^{10}$, respectively). Thus, InN ALD cannot be undertaken in an oxidizing atmosphere and chosen indium precursors suitable for ALD of $\operatorname{In}_{2} \mathrm{O}_{3}$ such as $\operatorname{In}(\mathrm{I}) \mathrm{Cp}$ cannot be used as there is nothing to oxidize the metal center to In(III).

When considering an ALD precursor for oxygen and carbon free deposition of indium nitride, the lack of oxygen and In-C bonds in the precursor is paramount, as is the +III oxidation state of the indium center. Tris-N,N,-dimethyl-N',N"diisopropylguanidinatoindium(III) (1) has previously been used as both a CVD precursor $^{11}$ as well as an ALD precursor ${ }^{12}$ for the deposition of indium oxide. This suggests that this precursor has an appropriate chemisorption chemistry to be further explored for nitride deposition. However, an in-depth reading of the principle literature on this compound suggests that it exhibits a complicated thermal behaviour that needs to be investigated further.

In a previous publication, $\mathbf{1}$ was seen to have an encouraging thermogravimetric (TG) trace, with the onset of volatility at approximately $60{ }^{\circ} \mathrm{C}$ and $85 \mathrm{mTorr}$ of vapor pressure at $150{ }^{\circ} \mathrm{C} .{ }^{11}$ The residual mass was about $12 \%$, and appeared to deposit indium metal. Chemical vapour deposition occurred above $275^{\circ} \mathrm{C}$ using air (i.e., $\mathrm{O}_{2}+\mathrm{H}_{2} \mathrm{O}$ from ambient conditions) and resulted in an amorphous film that could be annealed to crystalline, cubic indium oxide at $1125^{\circ} \mathrm{C}$. The film was found to contain $1-2 \%$ of indium metal as deposited.

The same compound was shown to exhibit ALD-type deposition in a well-defined thermal window from $230{ }^{\circ} \mathrm{C}-300{ }^{\circ} \mathrm{C},{ }^{12}$ which overlaps with the suggested CVD 
conditions. At a growth temperature of $240{ }^{\circ} \mathrm{C}$, the growth rate of $\operatorname{In}_{2} \mathrm{O}_{3}$ was found to plateau at $0.4-0.45 \AA$ /cycle at 4 seconds exposure, using water as the co-reactant. Although the errors bars are significant, the plateau has a slope that hints at a small CVD component. GI-XRD showed the deposited film to be crystalline above $180^{\circ} \mathrm{C}$, and XPS was used to determine that the film had appropriate stoichiometry.

In both previous reports, the thermal chemistry of $\mathbf{1}$ was seen to be complex. It showed some evidence of carbodiimide (CDI) elimination at temperatures as low as 110 ${ }^{\circ} \mathrm{C}$ in reference 11 , but was reported as stable up to $160^{\circ} \mathrm{C}$ in reference 12 . In both cases, complex thermal behaviour was suggested at higher temperatures, with diisopropylcarbodiimide reported as a potential decomposition product in both cases. This is expected, as aluminum guanidinates have previously shown carbodiimide elimination. The prime example of this was the monoguanidinatobisamidoaluminum(III) species which was seen to produce carbodiimide and homoleptic trisamidoaluminum(III) in the gas phase (Fig. 1).

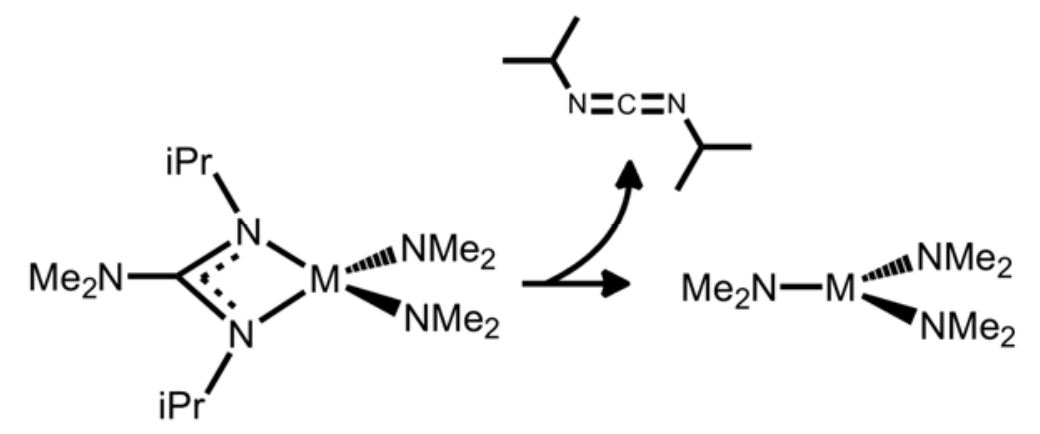

FIG. 1. Elimination of diisopropylcarbodiimide from trisguanidinato group 13 compounds $(\mathrm{M}=\mathrm{Al}, \mathrm{Ga})$.

The aluminum analogue of $\mathbf{1}$ was seen to undergo a low-temperature thermolysis at approximately $120^{\circ} \mathrm{C}$ by TG analysis, showing mass losses corresponding to 
carbodiimide elimination, although the carbodiimide was only seen as a thermolysis product in the solution phase. ${ }^{13}$ This suggests that there might be a thermal decomposition pathway for $\mathbf{1}$ that could produce a heteroleptic gas phase byproduct that acts as the deposition precursor (Fig. 2).

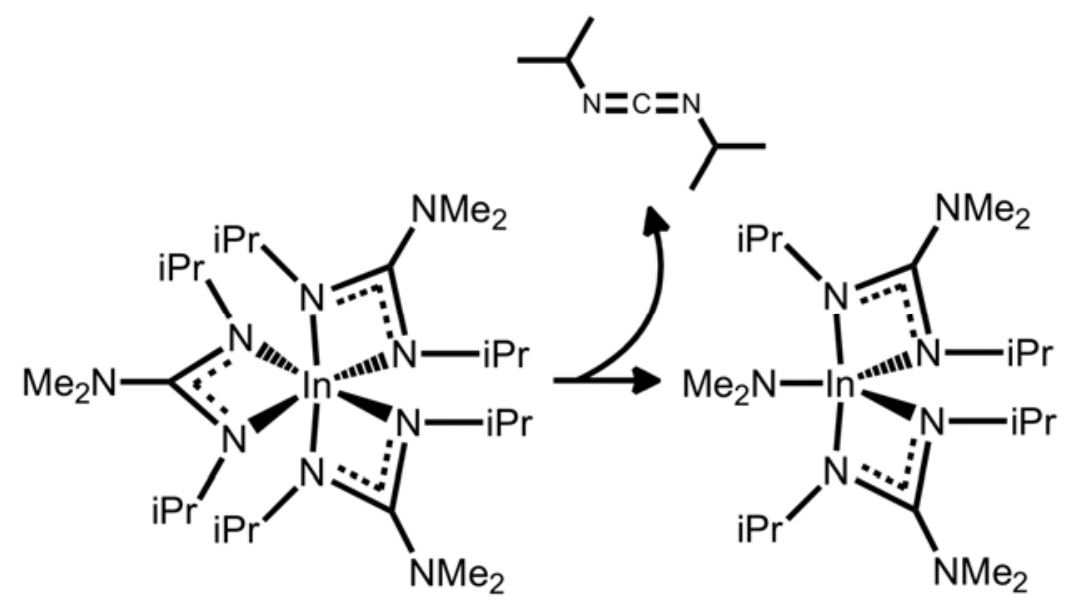

compound 1

compound 2

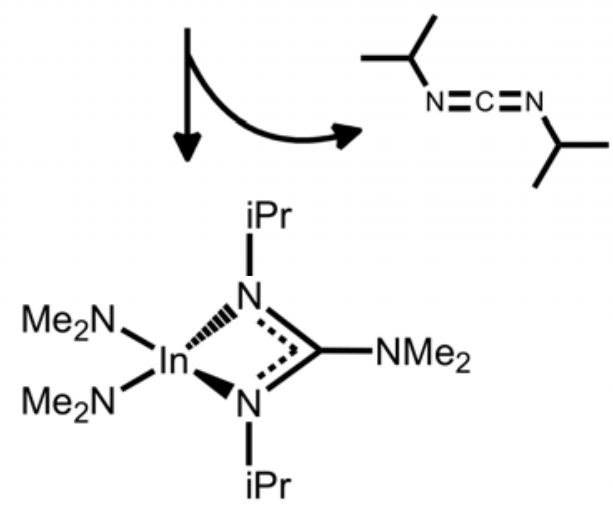

compound 3

FIG. 2. Carbodiimide elimination to produce heteroleptic indium (III) species.

This is an important aspect of group 13 guanidinate chemistry to understand, since the ligand environment of the deposition precursor greatly affects the surface chemistry of deposition. A recent paper by Devi and coworkers shows that, compared to trisamidinatoindium (III) compounds, ${ }^{14}$ heteroleptic bisamidinatomonomethylindium(III) compounds have a higher residual mass in the TG (14\% vs. $5 \%)$ and different 
crystallinity in the deposited indium oxide, suggesting different surface-precursor chemistry. Given that $\mathbf{1}$ was kept at $130{ }^{\circ} \mathrm{C}$ for $\mathrm{ALD}^{12}$ and $150{ }^{\circ} \mathrm{C}$ for $\mathrm{CVD},{ }^{11}$ the nature of this thermolysis needs to be better understood. Herein we report the synthesis of one of the intermediates of the carbodiimide elimination reaction, and discuss the thermolysis and likely fate of $\mathbf{1}$ when heated in a bubbler and in the gas phase.

\section{EXPERIMENTAL}

\section{A. Precursor Synthesis}

\section{1. $\left[\left(\mathrm{Me}_{2} \mathrm{~N}\right) \mathrm{C}\left(\mathrm{Ni}^{\mathrm{P} P r}\right)_{2}\right]_{3} \ln (1)$}

The synthesis of compound $\mathbf{1}$ was carried out in an MBraun Labmaster 300 nitrogen-filled glovebox. Firstly, a lithiated guanidinate species was synthesized by dissolving $\mathrm{LiNMe}_{2}(0.144 \mathrm{~g}, 2.7 \mathrm{mmol})$ in approximately $30 \mathrm{~mL}$ of hexanes and a few drops of ether in a $100-\mathrm{mL}$ flask with rapid stirring. In a separate vial, N,N'diisopropylcarbodiimide $(0.345 \mathrm{~g}, 2.7 \mathrm{mmol})$ was dissolved in approximately $10 \mathrm{~mL}$ of hexanes. Both solutions were placed in the freezer for 20 minutes at $-35^{\circ} \mathrm{C}$, then the carbodiimide solution was added dropwise by pipette to the $\mathrm{LiNMe}_{2}$ slurry. The mixture was allowed to warm to room temperature and was stirred overnight. The lithiated guanidinate product could not be isolated by drying, therefore, it was left in solution and used in the following synthetic step. ${ }^{1} \mathrm{H}$ NMR $\left(300 \mathrm{MHz}, \mathrm{C}_{6} \mathrm{D}_{6}\right): \delta 3.74$ [sept, $2 \mathrm{H}$, $\left.\mathrm{CH}\left(\mathrm{CH}_{3}\right)_{2}\right], 2.65\left[\mathrm{~s}, 6 \mathrm{H}, \mathrm{CN}\left(\mathrm{CH}_{3}\right)_{2}\right], 1.26\left[\mathrm{~d}, 12 \mathrm{H}, \mathrm{CH}\left(\mathrm{CH}_{3}\right)_{2}\right]$. Lithiated guanidinate (3.002 g, $16.9 \mathrm{mmol}$ ) was dissolved in $50 \mathrm{~mL}$ hexanes and indium trichloride (1282 g, 5.8 mmol) was dissolved in $30 \mathrm{~mL}$ hexanes with rapid stirring. Both solutions were placed in the freezer, and the lithiated guanidinate solution was subsequently added to the indium trichloride solution dropwise by pipette. The $\mathrm{LiCl}$ salt was removed by filtration and the 
resulting solution was dried down and taken back up in hexanes and filtered again. The solvent volume was reduced by vacuum and the product was isolated by recrystallization as colourless crystals in a $-35^{\circ} \mathrm{C}$ freezer $(2.542 \mathrm{~g}, 70.1 \%) .{ }^{1} \mathrm{H}$ NMR $\left(300 \mathrm{MHz}, \mathrm{C}_{6} \mathrm{D}_{6}\right): \delta$ 3.78 [sept, $\left.2 \mathrm{H}, \mathrm{CH}\left(\mathrm{CH}_{3}\right)_{2}\right], 2.67\left[\mathrm{~s}, 6 \mathrm{H}, \mathrm{CN}\left(\mathrm{CH}_{3}\right)_{2}\right], 1.50\left[\mathrm{~d}, 6 \mathrm{H}, \mathrm{CH}\left(\mathrm{CH}_{3}\right)_{2}\right], 1.36[\mathrm{~d}, 6 \mathrm{H}$, $\left.\mathrm{CH}\left(\mathrm{CH}_{3}\right)_{2}\right]$.

\section{2. $\quad\left[\left(\mathrm{Me}_{2} \mathrm{~N}\right) \mathrm{C}(\mathrm{NiPr})_{2}\right]_{2} \ln \left(\mathrm{NMe}_{2}\right)(2)$}

Compound $\mathbf{2}$ was prepared in an analogous manner as $\mathbf{1}$ substituting: lithiated guanidinate ( $5 \mathrm{~g}$ assumed, $28.2 \mathrm{mmol}$ ) in approximately $100 \mathrm{~mL}$ of hexanes, and indium trichloride (3.122 $\mathrm{g}, 14.1 \mathrm{mmol})$ was dissolved in $80 \mathrm{~mL}$ tetrahydrofuran. The intermediate $\left[\left(\mathrm{Me}_{2} \mathrm{~N}\right)\left(\mathrm{N}^{i} \mathrm{Pr}\right)_{2}\right]_{2} \mathrm{InCl}_{2}$ was isolated by recrystallization in hexanes $(3.245 \mathrm{~g}$, 46.9\%). ${ }^{1} \mathrm{H}$ NMR (300 MHz, $\left.\mathrm{C}_{6} \mathrm{D}_{6}\right): \delta 3.58$ [sept, $\left.2 \mathrm{H}, \mathrm{CH}\left(\mathrm{CH}_{3}\right)_{2}\right], 2.42[\mathrm{~s}, 6 \mathrm{H}$, $\left.\mathrm{CN}\left(\mathrm{CH}_{3}\right)_{2}\right], 1.34\left[\mathrm{~d}, 12 \mathrm{H}, \mathrm{CH}\left(\mathrm{CH}_{3}\right)_{2}\right]$. This intermediate $\left[\left(\mathrm{Me}_{2} \mathrm{~N}\right)\left(\mathrm{N}^{i} \mathrm{Pr}\right)_{2}\right]_{2} \mathrm{InCl}_{2}$ was dissolved quantitatively in $40 \mathrm{~mL}$ ether and stirred to dissolve while lithium dimethylamide $(0.340 \mathrm{~g}, 6.6 \mathrm{mmol})$ was dissolved in $40 \mathrm{~mL}$ ether; the two solutions were placed in the $-35^{\circ} \mathrm{C}$ freezer for 20 minutes after which the $\mathrm{LiNMe}_{2}$ solution was added to the $\left[\left(\mathrm{Me}_{2} \mathrm{~N}\right)(\mathrm{N} \text { Pr })_{2}\right]_{2} \mathrm{InCl}_{2}$ solution dropwise by pipette. Compound 2 was obtained as a viscous yellow liquid (1.096 g, 33.2\%). ${ }^{1} \mathrm{H}$ NMR (300 MHz, $\left.\mathrm{C}_{6} \mathrm{D}_{6}\right): \delta 3.61$ [sept, $2 \mathrm{H}$, $\left.\mathrm{CH}\left(\mathrm{CH}_{3}\right)_{2}\right], 3.20$ [s, 6H, InN(CH3) 2 ], 2.53 [s, 6H, $\left.\mathrm{CN}\left(\mathrm{CH}_{3}\right)_{2}\right], 1.30$ [d, $\left.6 \mathrm{H}, \mathrm{CH}\left(\mathrm{CH}_{3}\right)_{2}\right]$.

\section{B. Thermogravimetric Analysis}

For all TGA experiments, the same sequence of steps was followed on the TGA Q500 instrument inside a nitrogen-filled glovebox. The desired sample (between 10 and $30 \mathrm{mg}$ ) was placed on a tared platinum pan with nitrogen flow rates set to $60 \mathrm{sccm}$.

In ramped TGA experiments, the sample was placed on the pan and the furnace was heated at a rate of $10{ }^{\circ} \mathrm{C} /$ minute to $600{ }^{\circ} \mathrm{C}$. The mass loss profile for $\mathbf{1}$ showed a 
relatively clean volatilization curve without any obvious bumps indicative of decomposition, but had a residual mass of $16 \%$ (indicating some form of decomposition, possibly occurring simultaneously with volatilization). Compound 2 had a mass loss profile with various features indicative of decomposition and a residual mass of approximately $25 \%$.

Isothermal TGA experiments allowed the sample to be held at a constant temperature over the length of the experiment; the temperature chosen was roughly the temperature at which the ramp experiment demonstrated $1 \%$ mass loss of the compound. In its isotherm at $130^{\circ} \mathrm{C}$, compound $\mathbf{1}$ showed linear mass loss over time, but even after 1600 minutes of heating, the compound did not volatilize completely ( $70 \%$ mass remaining). At $150{ }^{\circ} \mathrm{C}$, the sample demonstrated a linear mass loss over time, until bottoming out at approximately $20 \%$ mass; this decomposition occurred after 200 minutes at $160^{\circ} \mathrm{C}$.

\section{NMR Tube Thermolysis}

In the NMR tube thermolysis experiment of $\mathbf{1}$, a traditional NMR thermolysis was performed. A thick-walled NMR tube was filled with a sample of $\mathbf{1}$ inside the nitrogen glovebox. The sample was then dissolved in $\mathrm{d}_{6}$-benzene under an atmosphere of nitrogen on a Schlenk line. The NMR tube was flame sealed under vacuum on a Schlenk line after being under at atmosphere of argon gas. For the length of the experiment, the NMR tube was placed in a closed oven set at $150^{\circ} \mathrm{C}$.

After 1 hour at $150{ }^{\circ} \mathrm{C}$, an ${ }^{1} \mathrm{H}$ NMR showed, aside from the expected peaks for $\mathbf{1}$, additional small peaks for N,N'-diiosopropylcarbodiimide (CDI) and protonated guanidine. The septets for both decomposition products (CDI and protonated guanidine) 
were overlapping, so their collective integration was calculated and compared to that of 1; note that these comparisons take into account that one molecule of precursor would decompose to three of either products. It is also important to note that over the course of these experiments, a brown insoluble product formed and was visible in the tube; due to its insolubility it was likely not represented in the NMR spectrum and its presence increased with increased heating and time.

After the first hour of heating at $150^{\circ} \mathrm{C}$, the ratio of $\mathbf{1}$ to its decomposition products was approximately 4.7. Over a period of five hours, the decomposition products' appearance increased to raise the former ratio to 3.7. After a further 43 hours of heating at $150{ }^{\circ} \mathrm{C}$, the ratio only further increased to 3.3. Over all time that $\mathbf{1}$ was heated at $150^{\circ} \mathrm{C}$, the ratio of $\mathrm{CDI}$ to guanidine in the NMR spectrum remained relatively constant, decreasing slightly from 1.6 to 1.4 . The ratio of $\mathbf{1}$ to CDI decreased from $\sim 6.2$ to 4.6 , and the ratio of $\mathbf{1}$ to guanidine from 10.0 to 6.4 . This is to say that $\mathbf{1}$ was certainly decomposing over time at $150^{\circ} \mathrm{C}$, and decomposition to CDI was much more prevalent than to guanidine.

The temperature of the oven was then increased to $160^{\circ} \mathrm{C}$. Over the first five hours at this temperature, the ratio of $\mathbf{1}$ to decomposition products remained constant around 3.3. The tube was then left to heat over time periods of 24 hours or greater; after 167 hours at $160^{\circ} \mathrm{C}$ (on top of the 48 hours at $150^{\circ} \mathrm{C}$ ), the ratio of $\mathbf{1}$ to decomposition products had increased to 1.93 . The ratio of CDI to guanidine increased to 1.3.

The NMR tube was subsequently heated at $170^{\circ} \mathrm{C}$. After 24 hours, the ratio of precursor to decomposed product increased to 1.68 , and after a further 72 hours, the ratio 
increased to $\sim 1.1$; the ratio of CDI to guanidine remained relatively constant from previous heating. The ratio continued to decrease over the next 24 hours to just below 1 .

Upon increasing the temperature to $180^{\circ} \mathrm{C}$ for 24 hours, the ratio of precursor to decomposed products decreased to 0.7 with the CDI:guanidine ratio constant around 1.3. After a final 24 hours of heating at $180^{\circ} \mathrm{C}$, the ratio of $\mathbf{1}$ to decomposition products increased to 0.5 and the ratio of CDI to guanidine varied slightly to 1.1 .

\section{MODELLING}

All quantum chemical computations were made with the Gaussian 09 software. ${ }^{15}$ Geometry optimization and frequency calculations were performed with the hybrid DFT functional B3LYP ${ }^{16,17}$ and with $6-31+\mathrm{G}(\mathrm{d}, \mathrm{p})$ basis for lighter atoms and Los Almos double-zeta basis with associated effective core potential (lanl2dz) for indium. The method and basis have earlier been shown to give accurate values for structures of indium compounds. ${ }^{18}$ The geometries were verified to have none imaginary frequencies for the minima and one negative frequency along the reaction path for the transition states.

\section{IV.RESULTS AND DISCUSSION}

The computational elimination mechanism was modeled as the reverse CDI insertion mechanism onto aluminum reported earlier, ${ }^{19}$ and similar stationary structures were found along the predicted reaction path. The mechanism is composed of six stationary points: compound $\mathbf{1}$, a chelation transition state (TS1), a dechelated intermediate, a migration transition state (TS2), adduct, and finally separated compound 2 and CDI (Fig. 3). The relative electronic and free energies for the different stationary structures are given in Table 1, while geometries with key bond lengths are given as supplementary data. 
TABLE I. Relative electronic energy and free energy for the stationary points in the deinsertion mechanism from 1 to 2 (1st) and from 2 to 3 (2nd). Energy given in $\mathrm{kJ} / \mathrm{mol}$.

\begin{tabular}{llllllll|}
\hline \hline & & Reactant & TS1 & Intermediate & TS2 & Adduct & Separated \\
\hline 1st & $\Delta \mathrm{E}$ & 0.0 & 142.3 & 40.0 & 169.1 & 137.3 & 152.0 \\
& $\Delta \mathrm{G}(\mathrm{STP})$ & 0.0 & 132.0 & 33.4 & 148.8 & 110.6 & 52.4 \\
& $\Delta \mathrm{G}\left(240{ }^{\circ} \mathrm{C}\right)$ & 0.0 & 129.2 & 29.1 & 141.1 & 95.0 & -8.4 \\
2nd & $\Delta \mathrm{E}$ & 0.0 & & & & & 150.0 \\
& $\Delta \mathrm{G}(\mathrm{STP})$ & 0.0 & & & & & 61.5 \\
& $\Delta \mathrm{G}\left(240{ }^{\circ} \mathrm{C}\right)$ & 0.0 & & & & & 6.2 \\
\hline \hline
\end{tabular}<smiles>CC(C)N=C=N[NH+](C(C)C)C(C)C</smiles>

FIG. 3. Proposed elimination reaction of CDI from 1. Note that only the guanidinate affected by the elimination is shown, for simplicity.

Compound 1. In undecomposed 1 the guanidinate ligands were positioned symmetrically around a $\mathrm{C}_{3}$-axis. The indium nitrogen bonds showed a mixture of a coordinating and a covalent bonding resonating at the guanidinate core $(2.24 \AA)$. The 
bulky isopropyl groups caused the structure to become a densely packed ball covering the indium atom. The structure is similar to the previously obtained crystal structure. ${ }^{11}$

Chelation (TS1). During the chelation one of the formamidine nitrogen detaches from the indium and rotates away while the dimethylamine nitrogen rotates toward the indium atom. Both nitrogen are approximately at the same distance from the indium center (3.58 $\AA$ respectively $3.77 \AA$ ). The remaining formamidine nitrogen is drawn closer to the indium atom forming a covalent bond $(2.06 \AA)$.

Intermediate. The metastable intermediate was formed after further rotation allowing the lone pair on the dimethyl amine to coordinate to the indium center. As the structure is sterically relaxed the covalent nitrogen indium bond is somewhat elongated $(2.11 \AA)$. The migration barrier is slightly higher than the barrier for chelation in terms of electronic energy making it more probable for the intermediate to rechelate rather than migrate at low temperatures. The barrier difference for free energy is smaller and decreases with increased temperature indicating an equal probability for the reactions at higher temperatures.

Migration (TS2). During the migration, the dimethylamine nitrogen approached the indium center to form a covalent bond instead of coordinating ( 2.59 vs. $2.11 \AA$ ) while the previously covalent bond between the formamidine nitrogen and indium elongates to a coordinating bond (from 2.11 to $2.49 \AA$ ). At the same time, the bond between the dimethylamine nitrogen and the central carbon elongated and severed, while a second double bond was formed between the carbon and the amidine coordinating to the indium.

Adduct. The adduct had significantly higher electronic energy and enthalpy than $\mathbf{1}$ and the intermediate. Steric hindrance between the isopropyl groups on the CDI and the 
other guanidinates forced the CDI from the indium atom making a very weak coordinating bond $(3.97 \AA)$.

Separated. Separation of the adduct caused a slight increase in the electronic energy and enthalpy, but entropic factors permitted a significant drop in the free energy. As the temperature was increased in the model, the free energy decreased further. At standard temperature and pressure, $\mathbf{1}$ had the lowest energy, but at approximately $210{ }^{\circ} \mathrm{C}$ the separated products became lower in free energy. This confirms that the cause of CDI elimination is an increase in entropy.

$2^{\text {nd }}$ elimination. Reactant and product geometries for the elimination of CDI from 2 to 3 was also computed. The resulting energies were similar to the first, with the main difference being that the relative free energy of the second elimination was slightly higher $(10-20 \mathrm{~kJ} / \mathrm{mol})$ for all investigated temperatures.

Temperature dependence. The reaction free energy for both eliminations was decreased with increased temperature, as was expected for an entropically driven process (Fig. 4). The first elimination changed from endo- to exergonic at approximately $210{ }^{\circ} \mathrm{C}$ while the second changed at approximately $265^{\circ} \mathrm{C}$. The double elimination (the first followed by the second) also followed this trend but had a much steeper slope than single eliminations. The double elimination changed from endo- to exergonic at approximately $235^{\circ} \mathrm{C}$. 


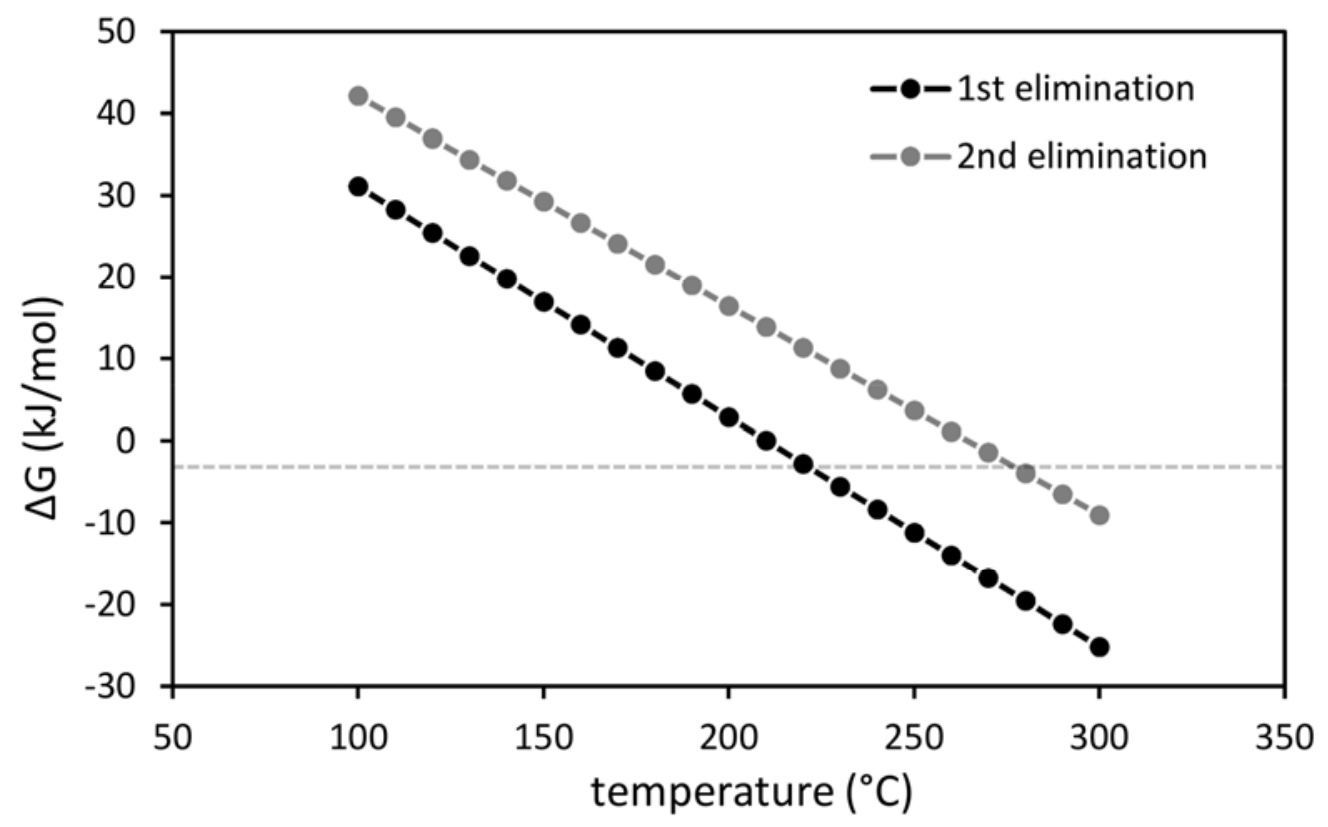

FIG. 4. Temperature dependence of CDI elimination from 1 to 2 ( $1^{\text {st }}$ elimination $)$ and from 2 to 3 ( $2^{\text {nd }}$ elimination).

Equilibrium. From the reaction free energy, the equilibrium constant and the equilibrium concentration of the species in the reaction could be calculated. When the partial pressure of $\mathbf{1}$ was set to 1 mbar (a reasonable vapour pressure for deposition experiments), it showed some decomposition even at room temperature, and at temperatures above $160^{\circ} \mathrm{C}$ it was almost fully decomposed (Fig. 5). The concentration profile shows similarities with the TG profile (vide infra). Compounds $\mathbf{1}$ and $\mathbf{2}$ were in a balanced equilibrium at about $120^{\circ} \mathrm{C}$, and compound 3 began to show an appreciable partial pressure at this temperature. At the temperature of the vaporization processes $\left(130{ }^{\circ} \mathrm{C}-150^{\circ} \mathrm{C}\right)$, both deinsertions could occur readily to produce 3. 


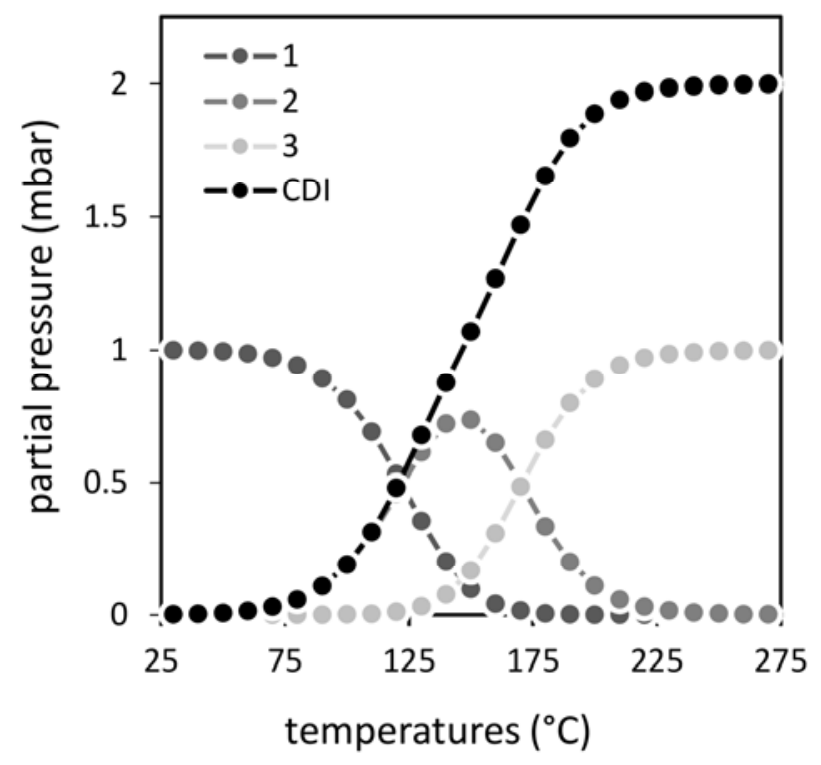

FIG. 5. The partial pressures from CDI elimination of $\mathbf{1}$ to produce $\mathbf{2}$ and $\mathbf{3}$.

Given the calculational conclusion that carbodiimide elimination is viable, an extended thermolysis testing was undertaken. In the literature, isotherms at $100{ }^{\circ} \mathrm{C}$ and $120^{\circ} \mathrm{C}$ were reported to be linear over 3.5 hours, ${ }^{12}$ and extended 8-hour isotherms of $\mathbf{1}$ showed similar behaviour (Fig. 6).

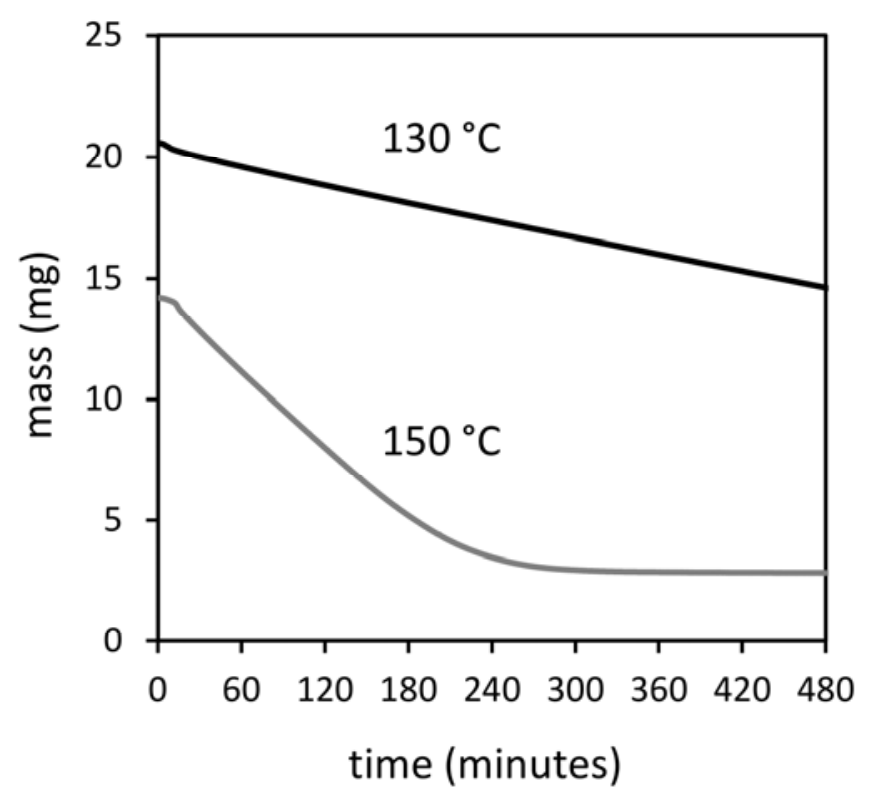


FIG. 6. Isotherms of 1 at $130^{\circ} \mathrm{C}$ (black) and $150^{\circ} \mathrm{C}$ (grey) over eight hours.

The isotherms remained linear during mass loss at both $130{ }^{\circ} \mathrm{C}$ and $150{ }^{\circ} \mathrm{C}(\mathrm{N}$. B., the slight modulation at the top of each trace was due to ramping the TG to the set point temperatures). The isotherm at $130{ }^{\circ} \mathrm{C}$ showed a modest $0.013 \mathrm{mg} /$ minute weight loss while the $150{ }^{\circ} \mathrm{C}$ showed $0.051 \mathrm{mg} /$ minute loss. The isotherm at $130{ }^{\circ} \mathrm{C}$ could not reasonably be run to completion since it would require a greater than 1600 minute experiment, but at $150{ }^{\circ} \mathrm{C}$, the linear weight loss had a $20 \%$ residual mass. This means that decomposition to a non-volatile side product and evaporation occurred at the same rate throughout the $150{ }^{\circ} \mathrm{C}$ isotherm, suggesting that these two events are coupled.

Elimination of carbodiimide would produce bis-N,N,-dimethyl-N',N"diisopropyl dimethylamido guanidinatoindium(III) (2, Fig. 2). This compound was synthesized as a yellow liquid in low yield by two successive salt metathesis reactions, beginning with indium trichloride: with the lithium guanidinate and two equivalents of amide, respectively. Compound $\mathbf{2}$ was found to have a poor TG trace, with several decomposition features (Fig. 7b).
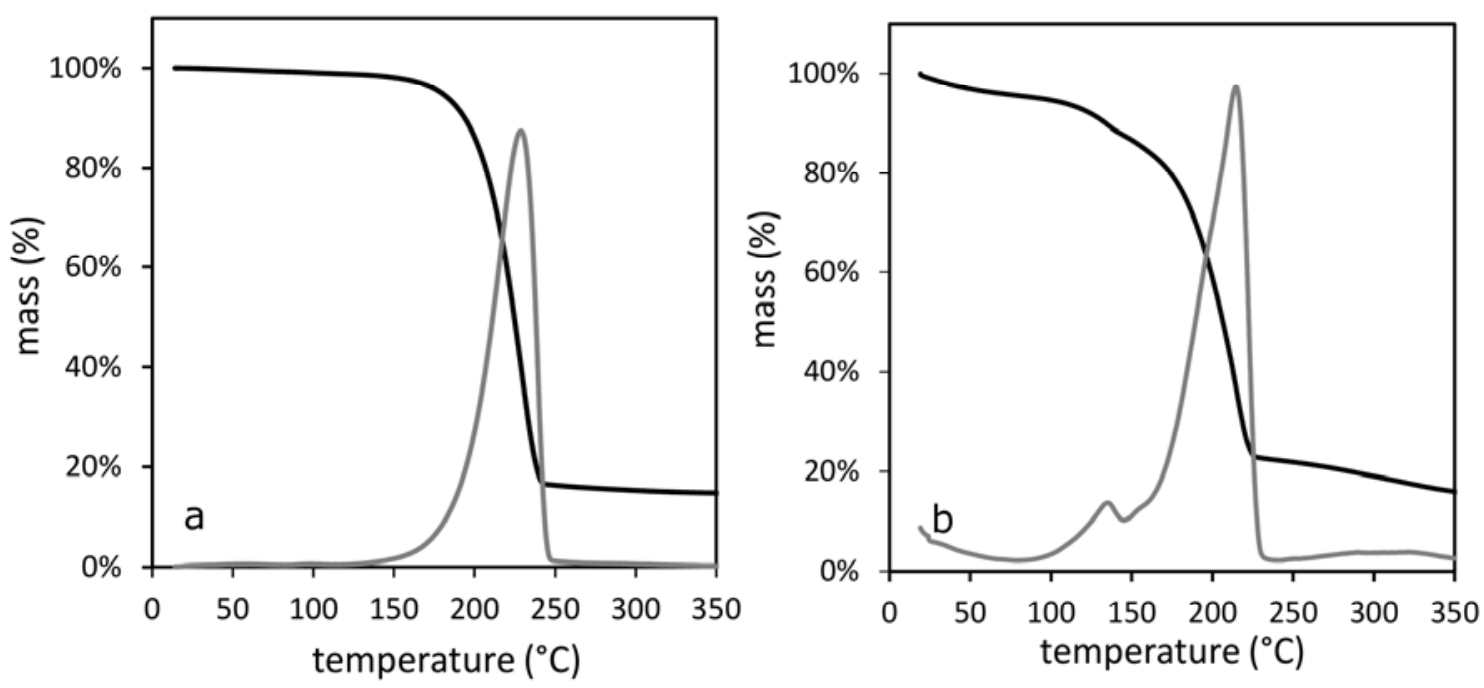
FIG. 7. Standard ramp TGs of compounds $\mathbf{1}$ (a) and $\mathbf{2}$ (b). Derivative curves are in grey.

The thermolysis of $\mathbf{2}$ was enlightening in understanding the thermal chemistry of 1. Although $\mathbf{1}$ appeared to have a suitable TG trace with a derivative curve representative of volatilization (Fig. 7a), the high residual mass suggested decomposition was occurring. The presence of carbodiimide in the previous thermolyses ${ }^{1} \mathrm{H} N M R^{11,12}$ suggests that $\mathbf{1}$ is at least partially converting to $\mathbf{2}$, or another heteroleptic derivative of $\mathbf{1}$. The TG for $\mathbf{2}$ showed more resolved decomposition and volatilization steps, and had a significantly high residual mass (25\%) that itself continued to decompose as the temperature increased (Fig. 7b). The residual mass was a grey, charred solid. The ${ }^{1} \mathrm{H}$ NMR evidence from sealed, thermolyzed samples again showed CDI elimination, suggesting that the residual mass is somehow related to the monoguanidinato species 3 (Fig. 2).

Synthetic efforts to make and isolate 3 were surprisingly unsuccessful, with the reaction mass becoming a viscous, intractable paste. Although several methods of workup were employed, no characterizable material could be isolated from the reaction mixture. We hypothesize that the low coordination number and the large indium centre together allowed the material to form a large order oligomer (or possibly a polymer), preventing isolation. However, this fits well with the thermal chemistry seen above. If $\mathbf{1}$ underwent successive CDI eliminations to ultimately form a non-volatile polymer of $\mathbf{3}$, this would provide the residual mass seen in both TG traces in Fig. 7.

The evolution of CDI from $\mathbf{1}$ was followed over two weeks in a sealed NMR tube. The tube was heated in steps to $150{ }^{\circ} \mathrm{C}(2$ days $), 160{ }^{\circ} \mathrm{C}$ ( 7 days $), 170{ }^{\circ} \mathrm{C}$ ( 3 days), and $180^{\circ} \mathrm{C}(2$ days) (Fig. 8). 


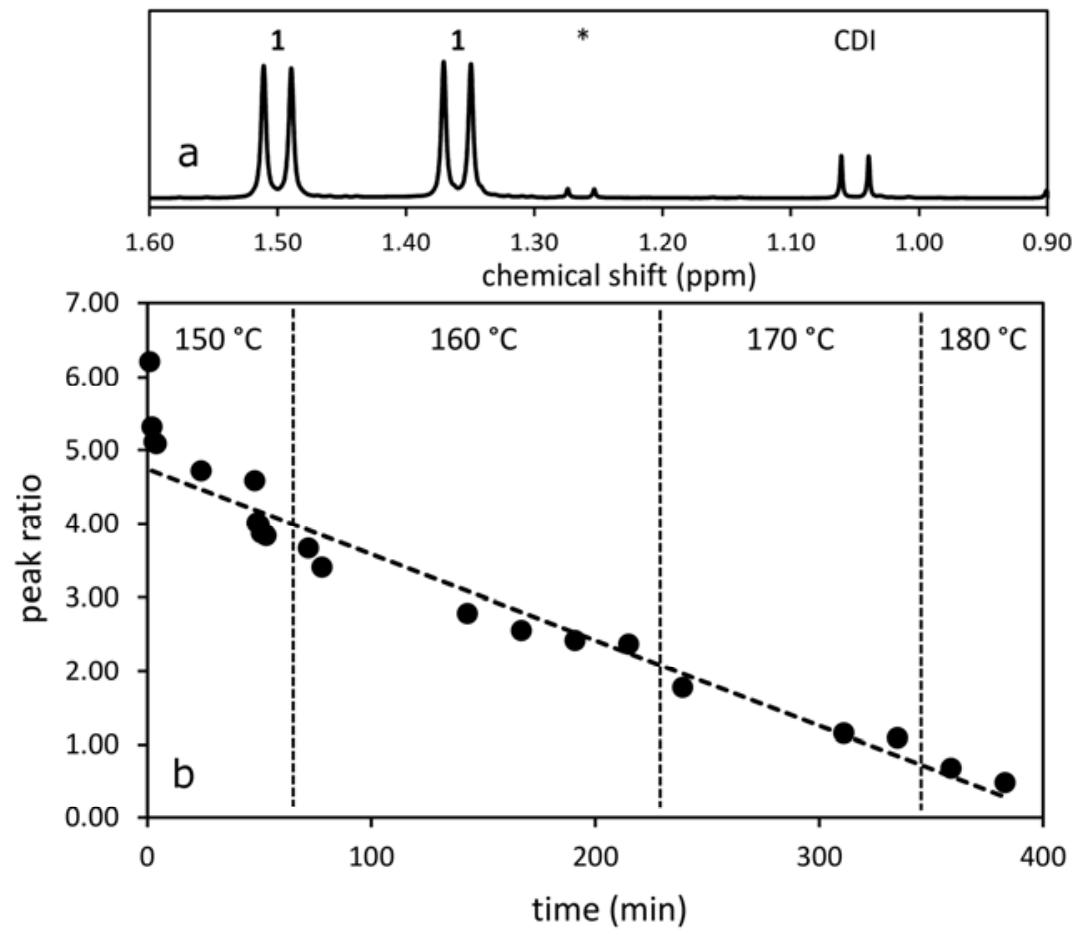

FIG. 8. The ${ }^{1} \mathrm{H}$ NMR study of thermolysis of 1 . a) the NMR peaks used to determine thermolysis (* shows the minor guanidine thermolysis product). b) a graph of the ratio of the areas for 1 vs. CDI. The coefficient of determination $\left(\mathrm{R}^{2}\right)$ was 0.96 for the fitted line.

The peak ratio in the ${ }^{1} \mathrm{H}$ NMR for the doublets of $\mathbf{1}$ against the doublet for CDI (Fig. 8a) showed that the rate of decomposition was relatively constant over 2 weeks, even as temperature was raised from $150{ }^{\circ} \mathrm{C}$ to $180{ }^{\circ} \mathrm{C}$. It should be noted that the first two data points (within 2 hours of sealing and heating the tube) were excluded.

Commonly, even the most carefully sealed tube will show degradation of the product due to flame-sealing the NMR tube. The constant decline of $\mathbf{1}$ over this temperature range again demonstrated the thermal instability at temperatures near the necessary bubbler temperature of $\mathbf{1}$, and suggested further that CDI was a major by-product of decomposition. However, the ${ }^{1} \mathrm{H}$ NMR also showed characteristic peaks for protonated 
guanidine, as well as other septet and doublet environments that represent environments of 2 and potentially other isopropyl-containing ligand environments. This showed that CDI elimination was not the only thermal process that $\mathbf{1}$ undergoes. Additionally, the quantification of these data is provisory: there was significant precipitate that formed during the thermolysis. Again, we suspect this to be intractable 3, but this material was uncharacterized.

\section{SUMMARY AND CONCLUSIONS}

Compund 1 showed a low-lying and complex thermolysis that could affect its use in deposition conditions. The previously reported temperatures for evolving vapor from $\mathbf{1}$ were $130{ }^{\circ} \mathrm{C}^{12}$ for ALD and $150{ }^{\circ} \mathrm{C}^{11}$ for CVD. The thermolysis of $\mathbf{1}$ to the intermediate bisguanidinate 2 and ultimately to the non-volatile monoguanidinate 3 through CDI elimination was calculated to establish an equilibrium around $120^{\circ} \mathrm{C}$, with both CDI elimination steps being thermodynamically favorable above $230^{\circ} \mathrm{C}$. The precursor can therefore be used as a deposition precursor, but its decomposition in the bubbler is expected to start immediately.

The decomposition studies by ${ }^{1} \mathrm{H}$ NMR suggest that the decomposition will occur over a period of weeks, and that it is relatively insensitive to temperature in the range of $150{ }^{\circ} \mathrm{C}$ to $180^{\circ} \mathrm{C}$. The major product of decomposition is diisoproylcarbodiimide, and this elimination can lead having a vapor mixture containing both species $\mathbf{1}$ and $\mathbf{2}$, while also producing a nonvolatile decomposition byproduct 3 . Some free guanidine was also found as a byproduct of the NMR thermolysis experiment, but this pathway seems to be a significant minority. 
The precursor 1 has been successfully used in both CVD and ALD deposition conditions, but in both reported processes, there was noted difficulties with the precursor. After extensive thermal testing, it appears that the compound does not degrade significantly faster as temperature is increased, but has a steady thermal decomposition mainly due to carbodiimide elimination. This suggests that $\mathbf{1}$ can be successfully used for indium nitride deposition, but substantial amounts of precursor should not be stored in the bubbler for multiple runs. Rather, small amounts of precursor should be freshly isolated and used for each new experiment, to minimize thermal losses and to limit complicated surface chemistry by multiple gas phase species (e.g., 1, 2, carbodiimide, and guanidine). Deposition of indium nitride by plasma and thermal methods are presently being studied using this 1.

\section{ACKNOWLEDGMENTS}

This project was founded by the Swedish foundation for Strategic Research through the project "Time-resolved low temperature CVD for III-nitrides" (SSF-RMA 15-0018). HP acknowledges the Wenner-Gren foundations and the COST Action MP1402 'Hooking together European research in atomic layer deposition (HERALD) supported by COST (European Cooperation in Science and Technology) for funding for a sabbatical at Carleton University. STB and SCB acknowledge the Vinnova VINNMER Marie Curie incoming mobility program for funding for a sabbatical and research visits to Linköping University (Vinnova grant 2015-03714). HP and STB are very grateful for the networking support provided from the COST Action HERALD. LO acknowledges financial support from the Swedish Government Strategic Research Area in Materials 
Science on Functional Materials at Linköping University (Faculty Grant SFO Mat LiU No. 2009 00971). LO acknowledges super- computing resources were provided by the Swedish National Infrastructure for Computing (SNIC) and the Swedish National Supercomputer Centre (NSC) and the Swedish Research Council (VR grant 201605137_4).

${ }^{1}$ A. G. Bhuiyan, A. Hashimoto, and A. Yamamoto, J. Appl. Phys 94, 2779-2808 (2003).

${ }^{2}$ E. Bellotti, B. K. Doshi, K. F. Brennan, J. D. Albrecht, and P. P. Ruden, J. Appl. Phys. 85, 916-923 (1999).

${ }^{3}$ K. S. A. Butcher and T. L. Tansley, Superlattices Microstruct. 38, 1-37 (2005).

${ }^{4}$ S. V. Ivanov, T. V. Shubina, T. A. Komissarova and V. N. Jmerik, J. Cryst. Growth 403, $83-89$ (2014).

${ }^{5}$ S. Ruffenach, M. Moret, O. Briot and B. Gil, Phys. Stat. Sol. A 207, 9-18 (2010).

${ }^{6}$ N. Nepal, N. A. Mahadik, L. O. Nyakiti, S. B. Qadri, M. J. Mehl, J. K. Hite, and C. R. Eddy, Cryst. Growth Des. 13, 1485-1490 (2013).

${ }^{7}$ A. Haider, S. Kizir and N. Biyikli, AIP Advances 6, 045203 (2016).

${ }^{8}$ S. C. Buttera, D. J. Mandia, S. T. Barry, J. Vac. Sci. Technol. A 35, 01B128-1 - 01B128-7 (2017).

${ }^{9}$ J. R. Rumble, CRC Handbook of Chemistry and Physics, 98th ed. (CRC Press, Boca Raton, 2017).

${ }^{10}$ H. Saitoh, W. Utsumi and K. Aoki, J. Cryst. Growth 310, 473-476 (2008).

${ }^{11}$ P. G. Gordon, M. J. Ward, M. J. Heikkila, W. H. Monillas, G. P. A. Yap, M. Ritala, M. Leskalä, S. T. Barry, Dalton Trans. 40, 9425 (2011). 
${ }^{12}$ M. Gebhard, M. Hellwig, H. Parala, K. Xu, M. Winter, A. Devi, Dalton Trans. 43, 937-940 (2014).

${ }^{13}$ L. C. Ziffle, A. P. Kenney, S. T. Barry, J. Müller, Polyhedron 27, 1832-1840 (2008).

${ }^{14}$ M. Gebhard, M. Hellwig, A. Kroll, D. Rogalla, M. Winter, B. Mallick, A. Ludwig, M. Wiesing, A. D. Wieck, G. Grundmeier, A. Devi, Dalton Trans. 46, 10220-10231 (2017).

${ }^{15}$ Gaussian 09, Revision E.01, M. J. Frisch, G. W. Trucks, H. B. Schlegel, G. E. Scuseria, M. A. Robb, J. R. Cheeseman, G. Scalmani, V. Barone, B. Mennucci, G. A. Petersson, H. Nakatsuji, M. Caricato, X. Li, H. P. Hratchian, A. F. Izmaylov, J. Bloino, G. Zheng, J. L. Sonnenberg, M. Hada, M. Ehara, K. Toyota, R. Fukuda, J. Hasegawa, M. Ishida, T. Nakajima, Y. Honda, O. Kitao, H. Nakai, T. Vreven, J. A. Montgomery, Jr., J. E. Peralta, F. Ogliaro, M. Bearpark, J. J. Heyd, E. Brothers, K. N. Kudin, V. N. Staroverov, T. Keith, R. Kobayashi, J. Normand, K. Raghavachari, A. Rendell, J. C. Burant, S. S. Iyengar, J. Tomasi, M. Cossi, N. Rega, J. M. Millam, M. Klene, J. E. Knox, J. B. Cross, V. Bakken, C. Adamo, J. Jaramillo, R. Gomperts, R. E. Stratmann, O. Yazyev, A. J. Austin, R. Cammi, C. Pomelli, J. W. Ochterski, R. L. Martin, K. Morokuma, V. G. Zakrzewski, G. A. Voth, P. Salvador, J. J. Dannenberg, S. Dapprich, A. D. Daniels, O. Farkas, J. B. Foresman, J. V. Ortiz, J. Cioslowski, and D. J. Fox, Gaussian, Inc., Wallingford CT, 2013.

${ }^{16}$ A. D. Becke, J. Chem. Phys. 98, 5648-5652 (1993).

${ }^{17}$ C. Lee, W. Yang, R. G. Parr, Phys. Rev. B 37, 785-789 (1988).

${ }^{18}$ C. W. Bauschlicher, Jr., J. Phys. Chem. A 103, 6429-6432 (1999).

${ }^{19}$ C. N. Rowley, G. A. DiLabio, S. T. Barry, Inorg. Chem. 44, 1983-1991 (2005). 


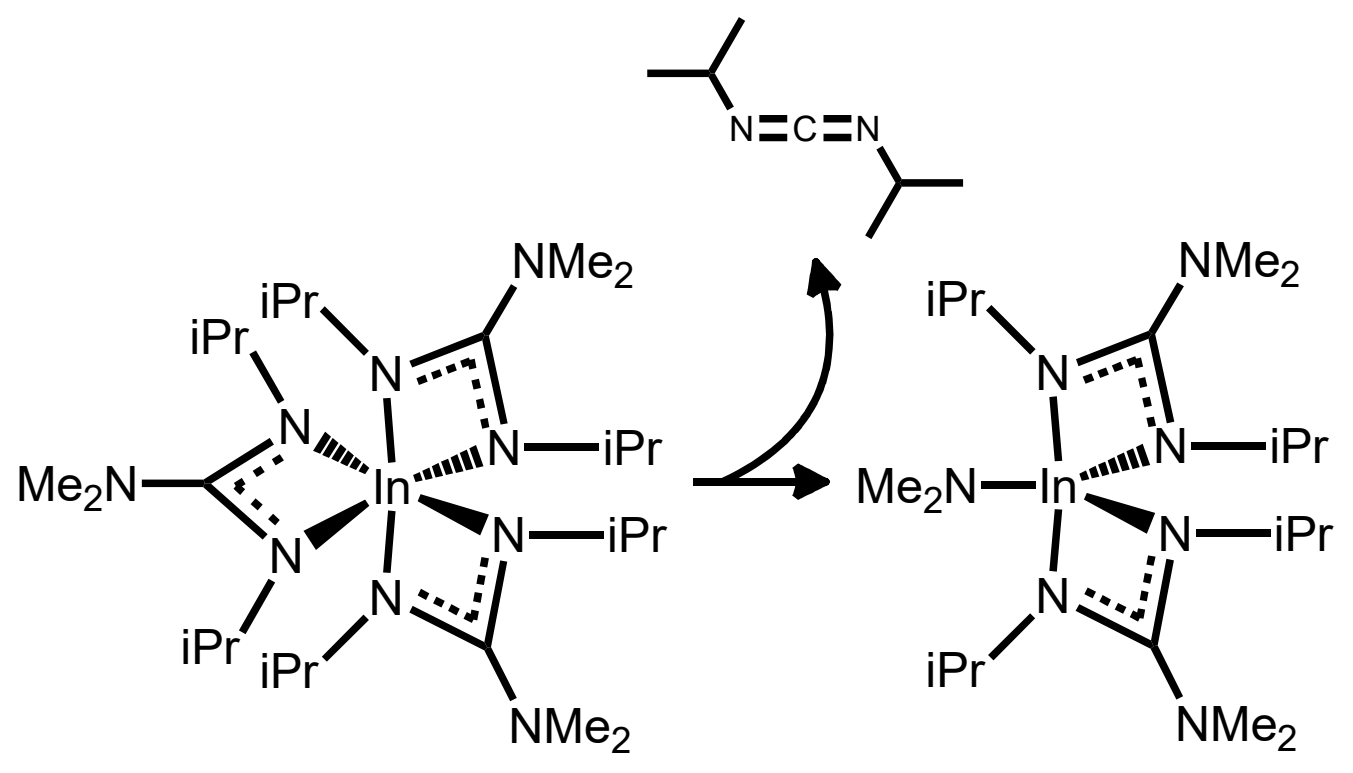

compound 1

compound 2
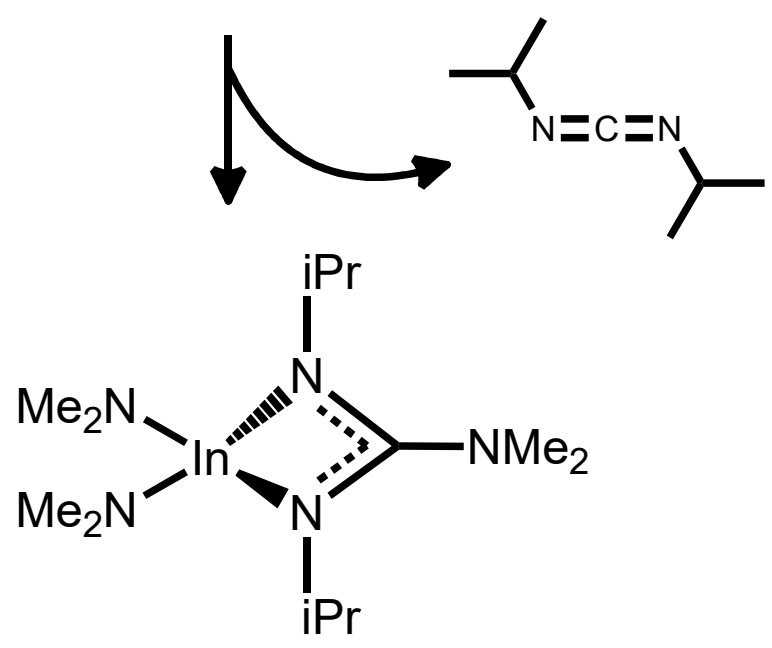

compound 3 



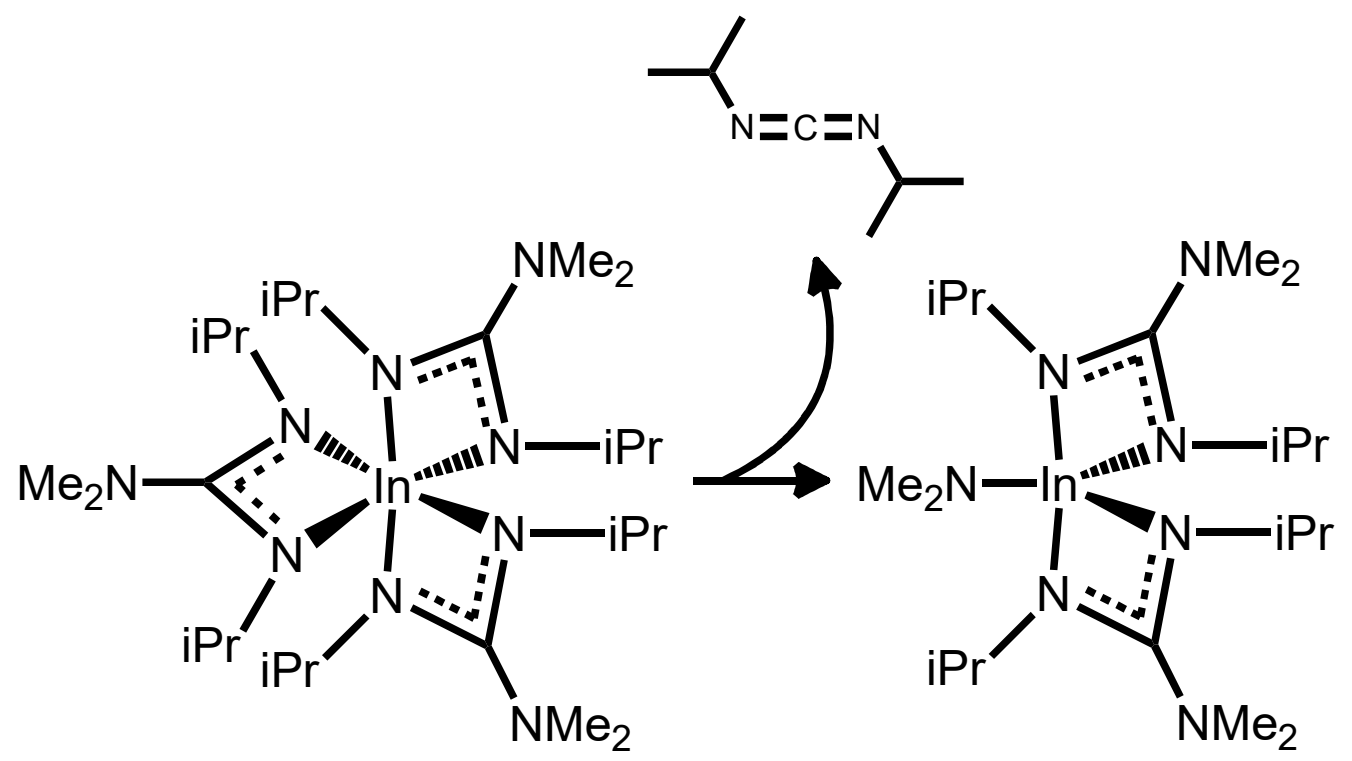

compound 1

compound 2

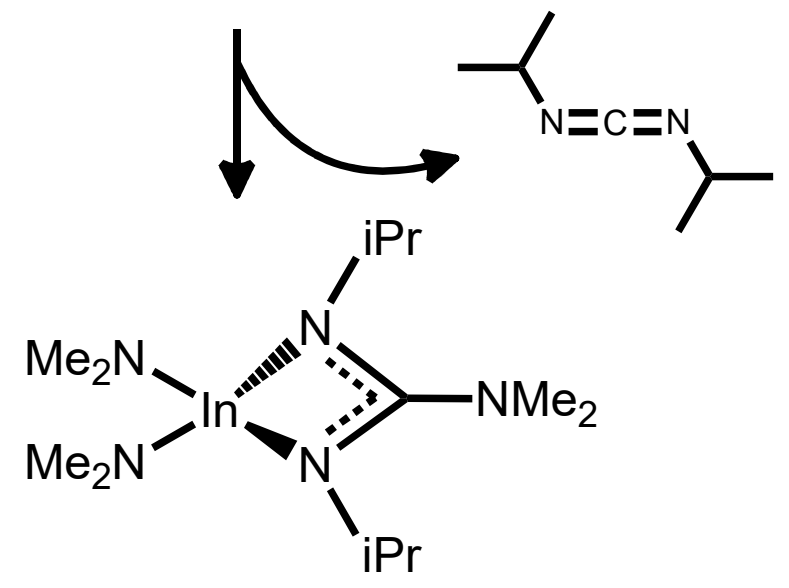

compound 3 


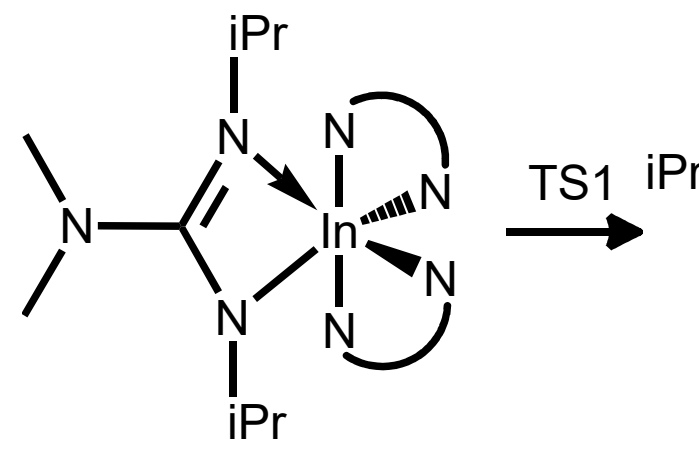

compound 1

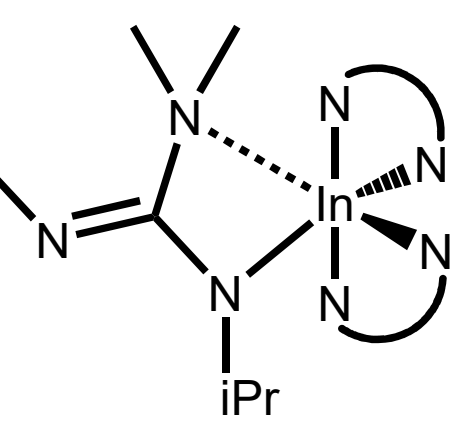

intermediate

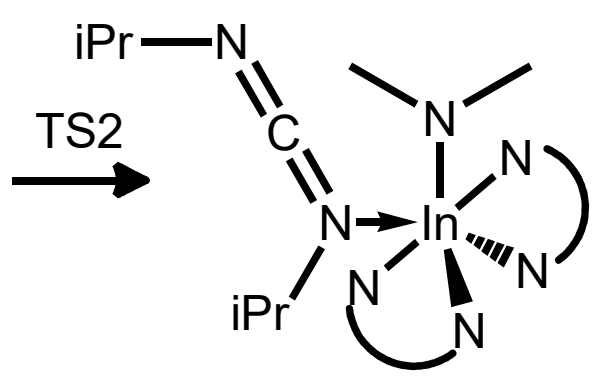

adduct

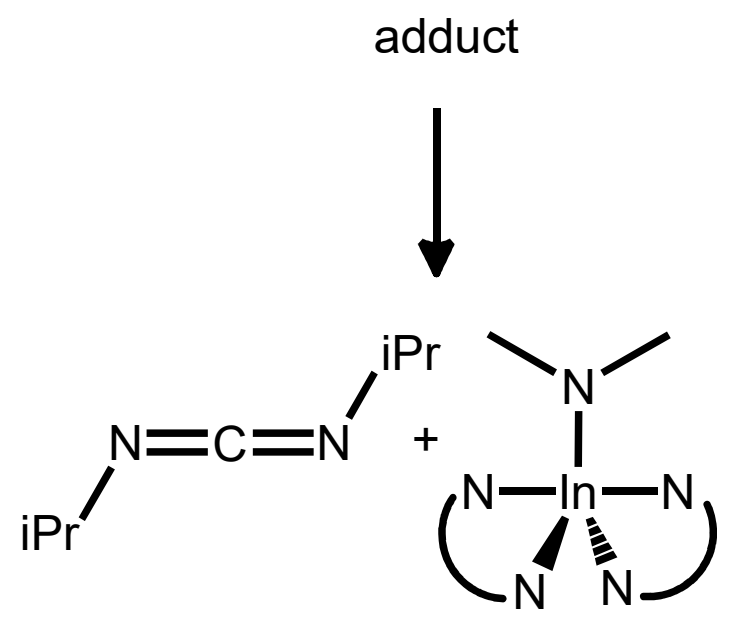

separated $\overbrace{\mathrm{N}}^{\text {represents unaffected }} \begin{gathered}\text { guanidinate ligands } \\ \text { guand }\end{gathered}$ 



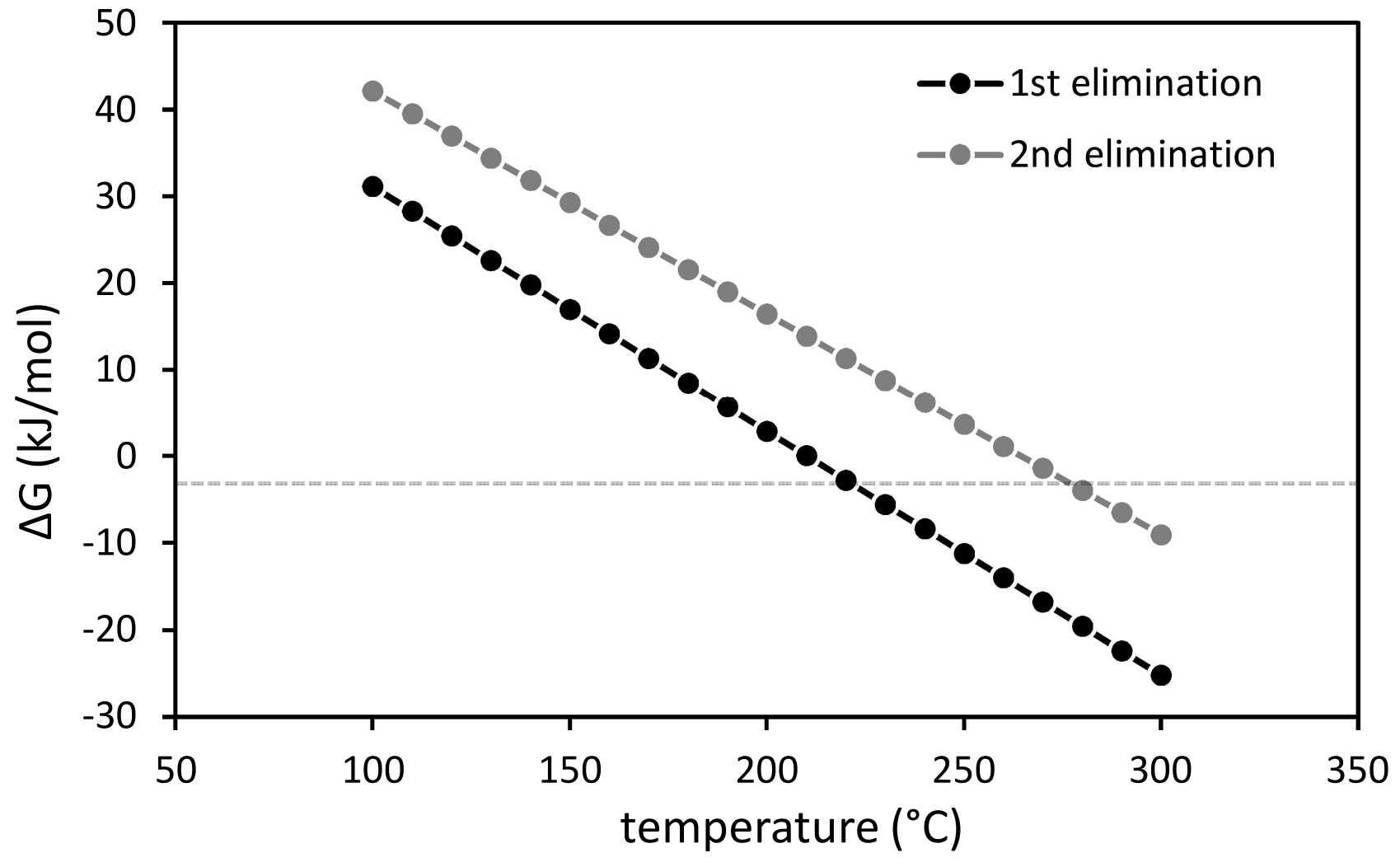




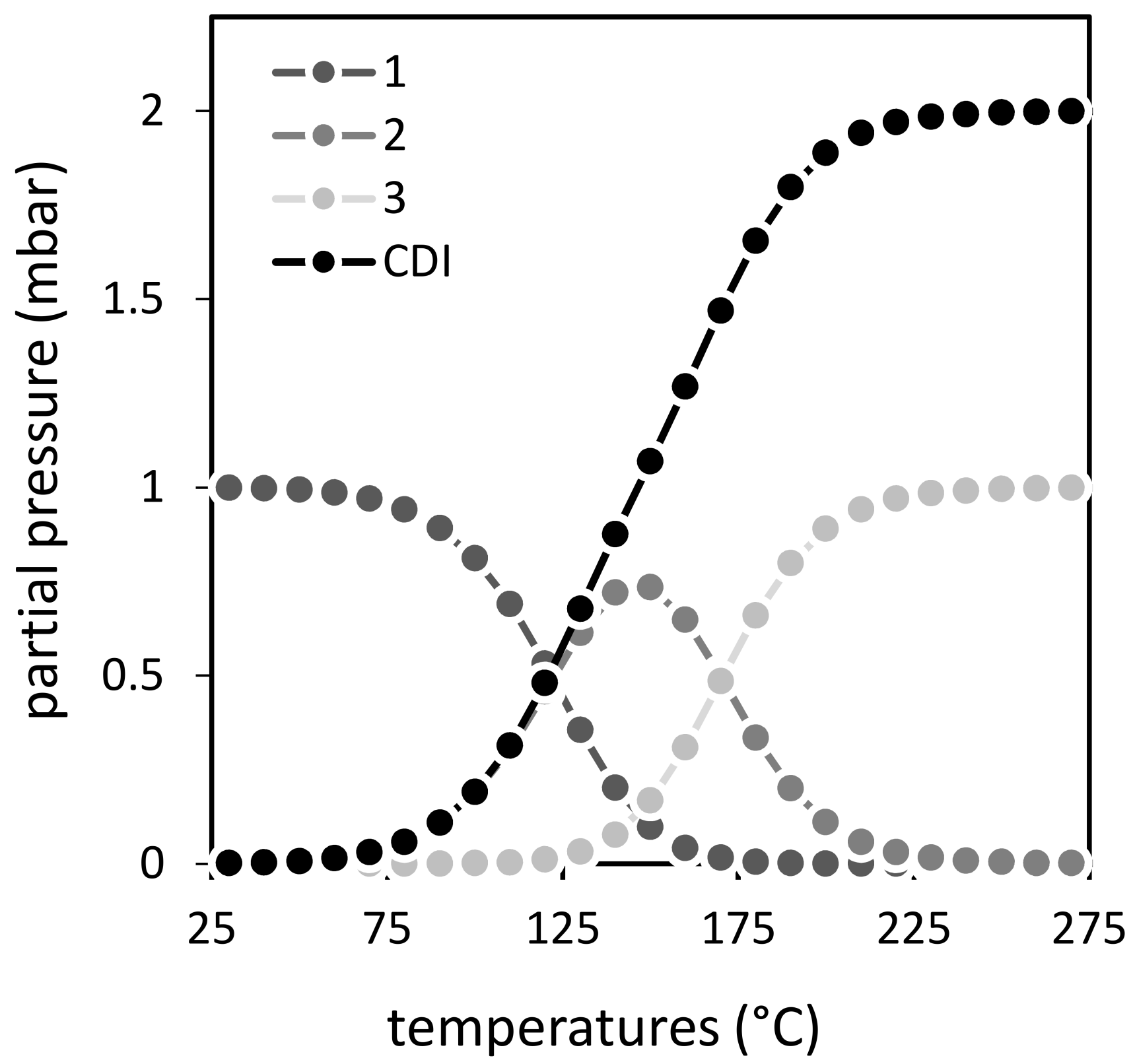




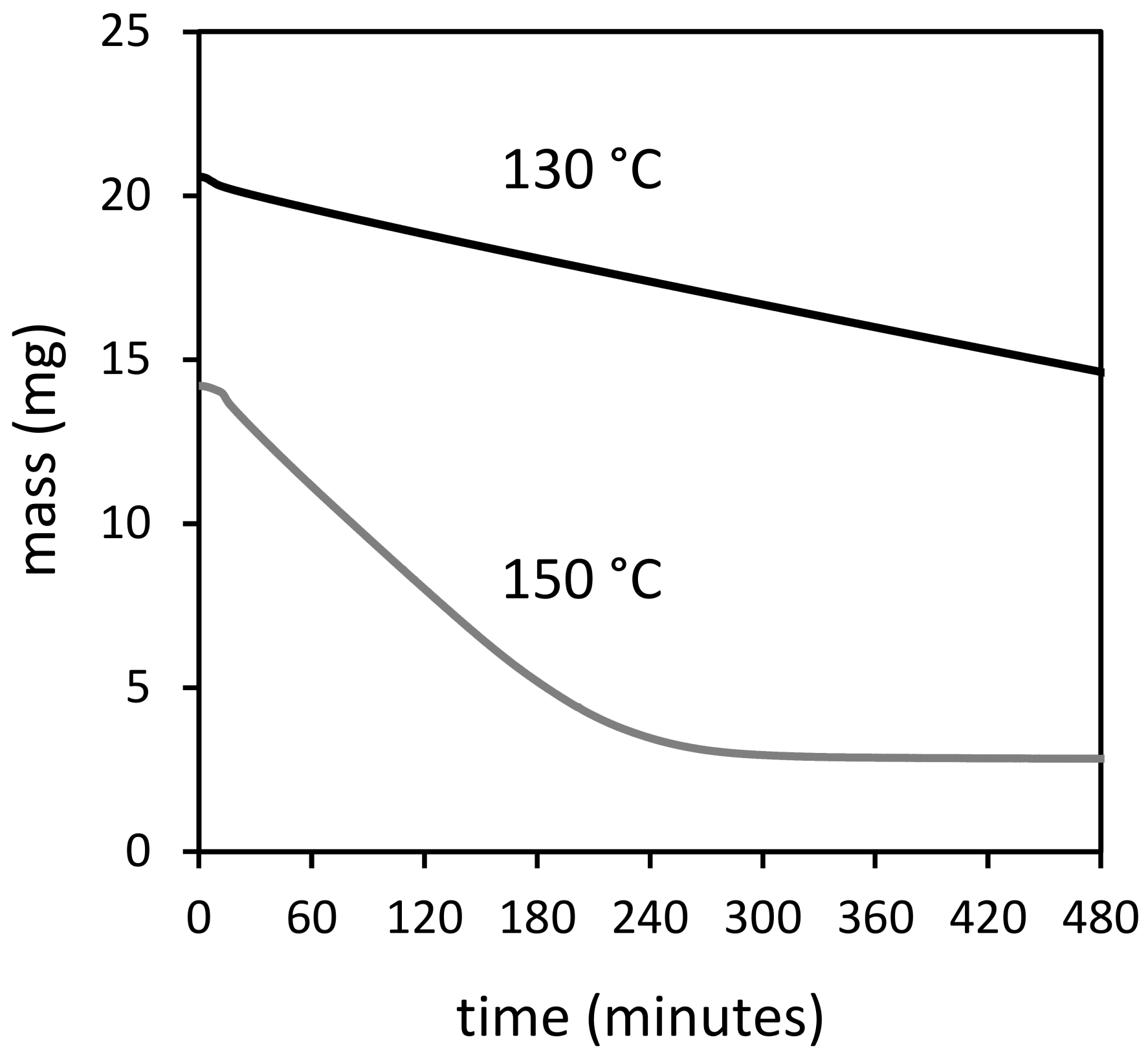



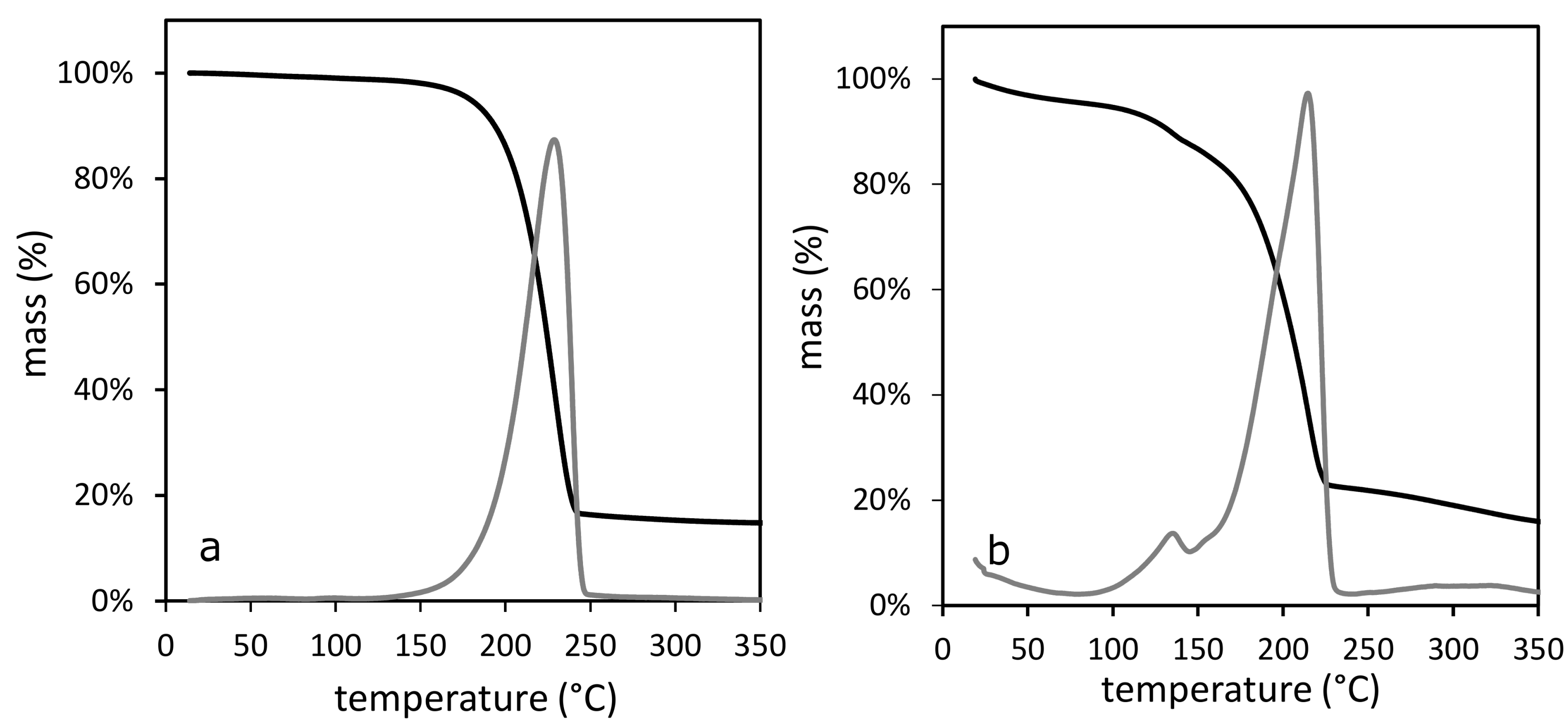


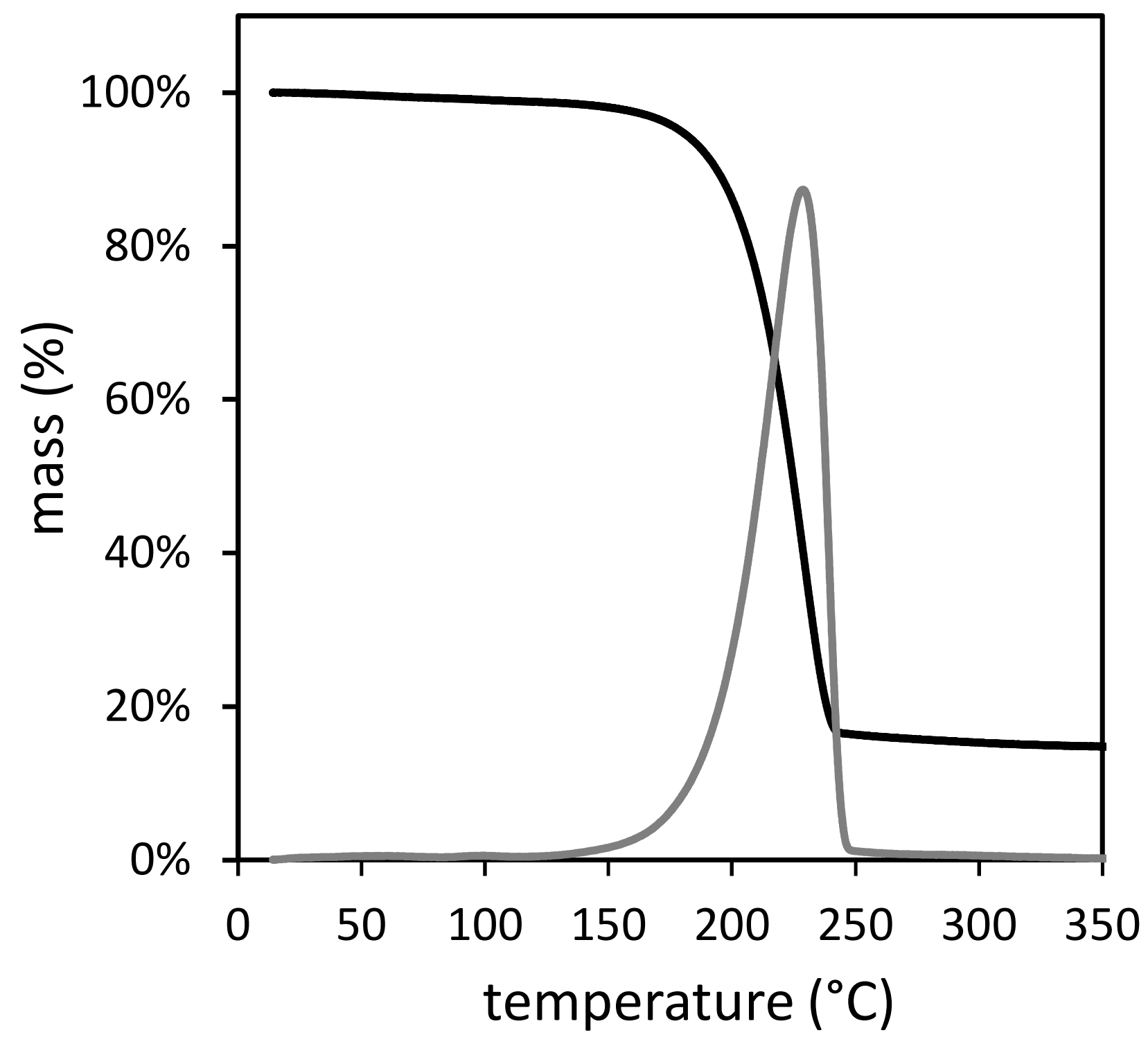




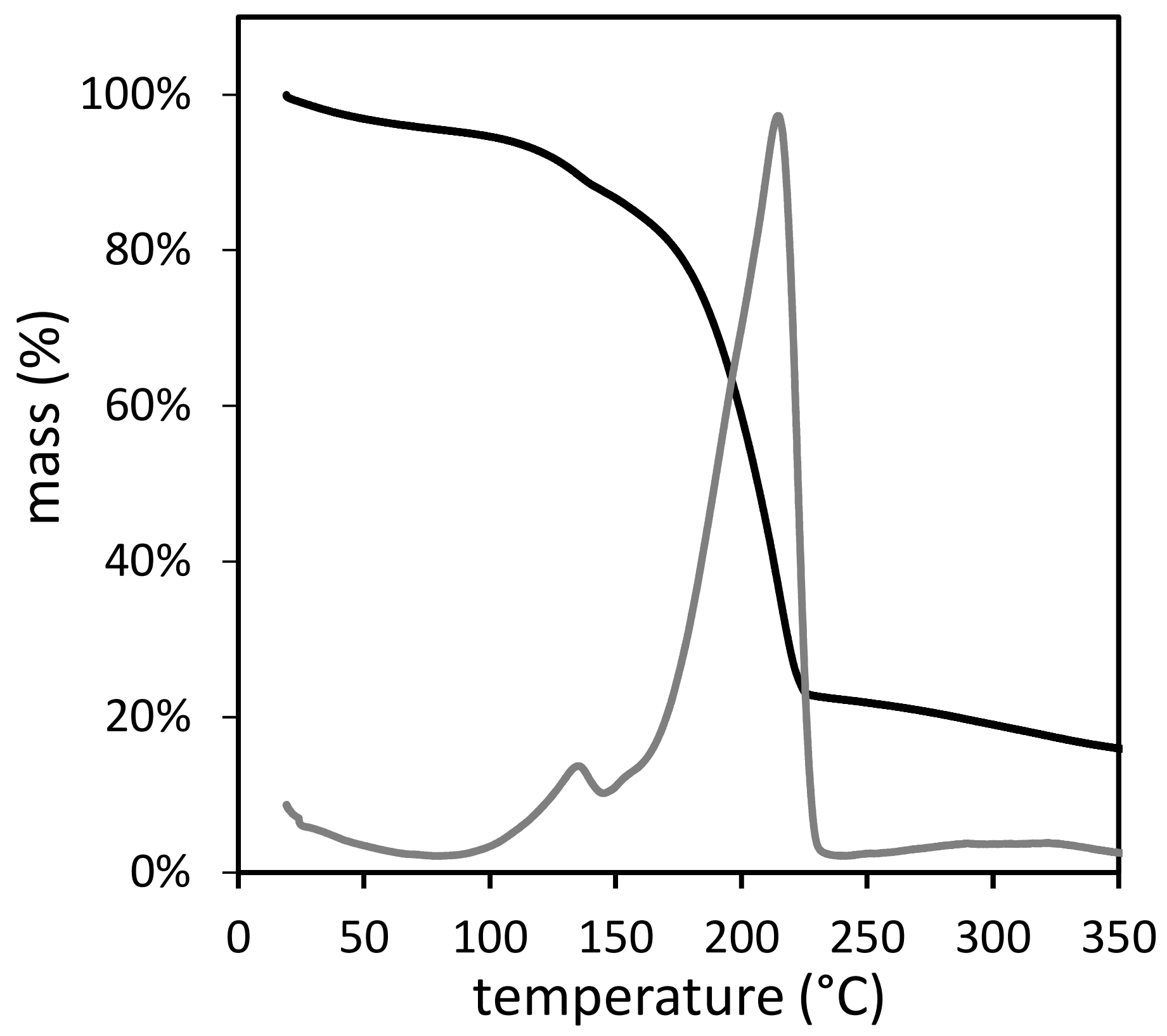




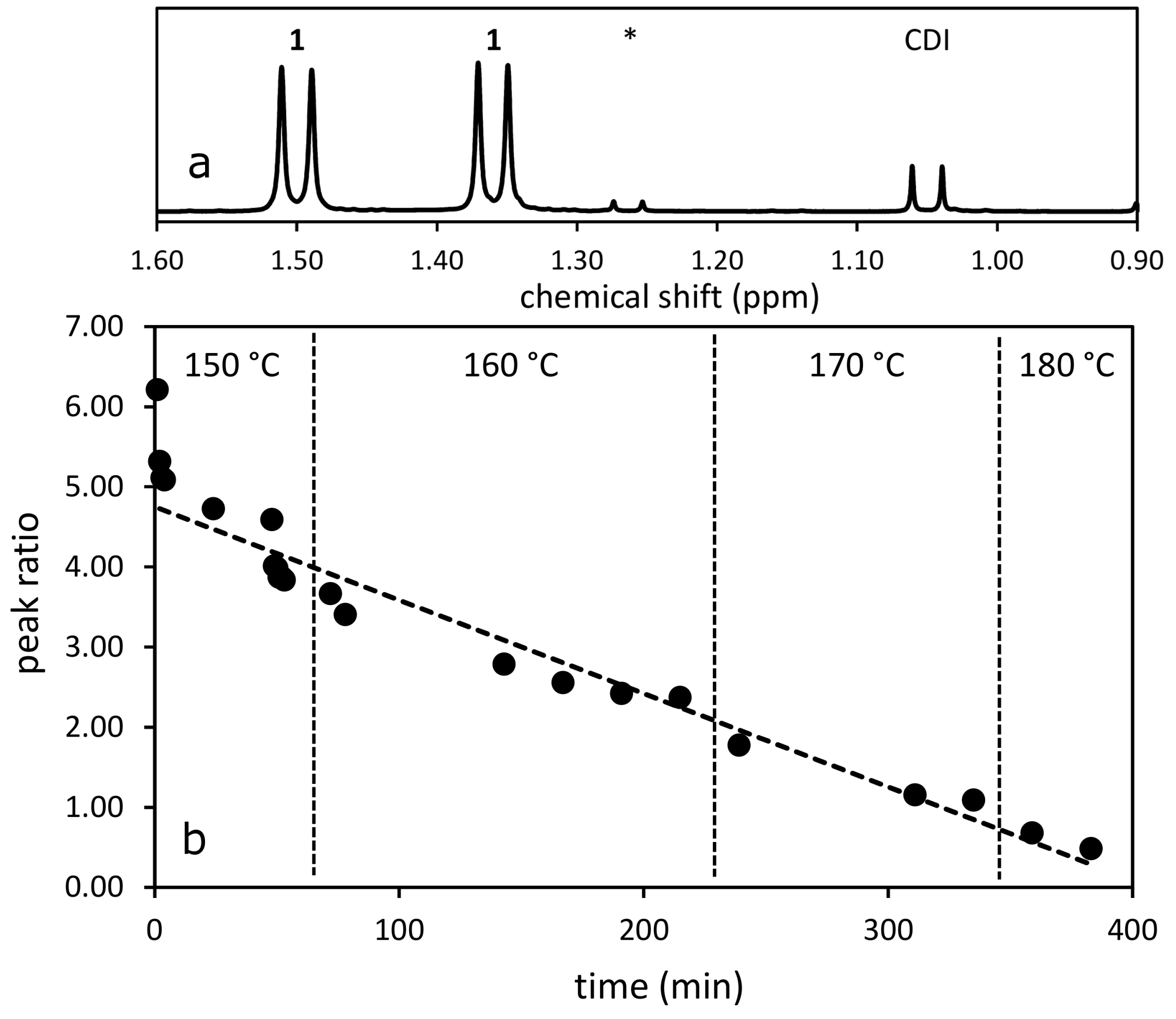




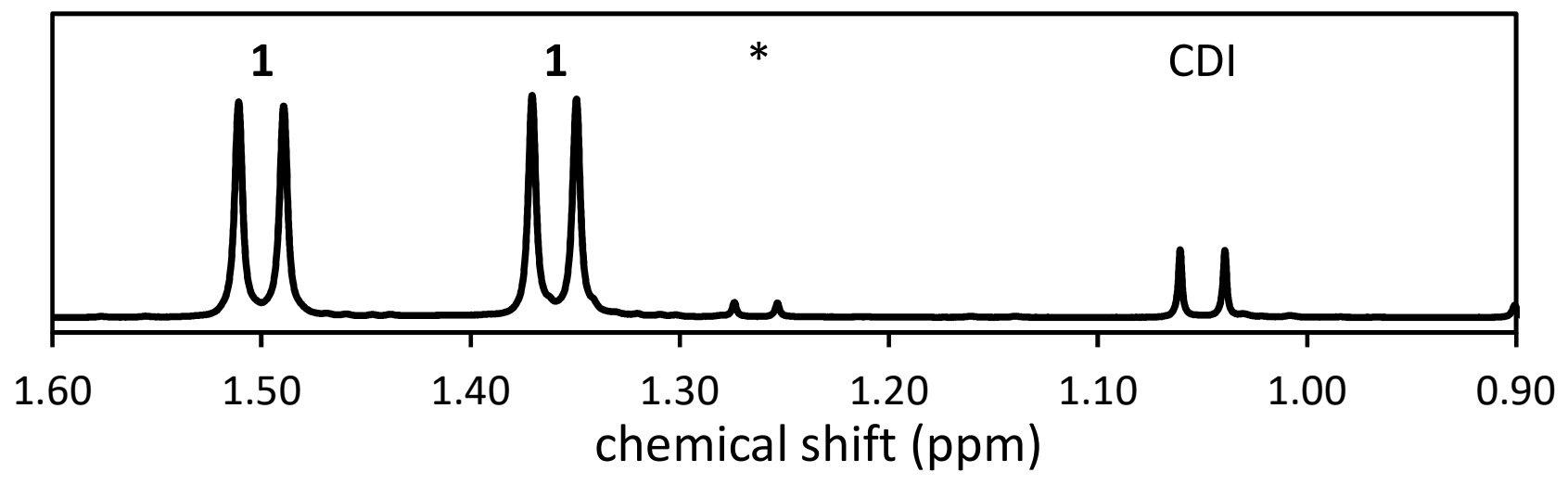




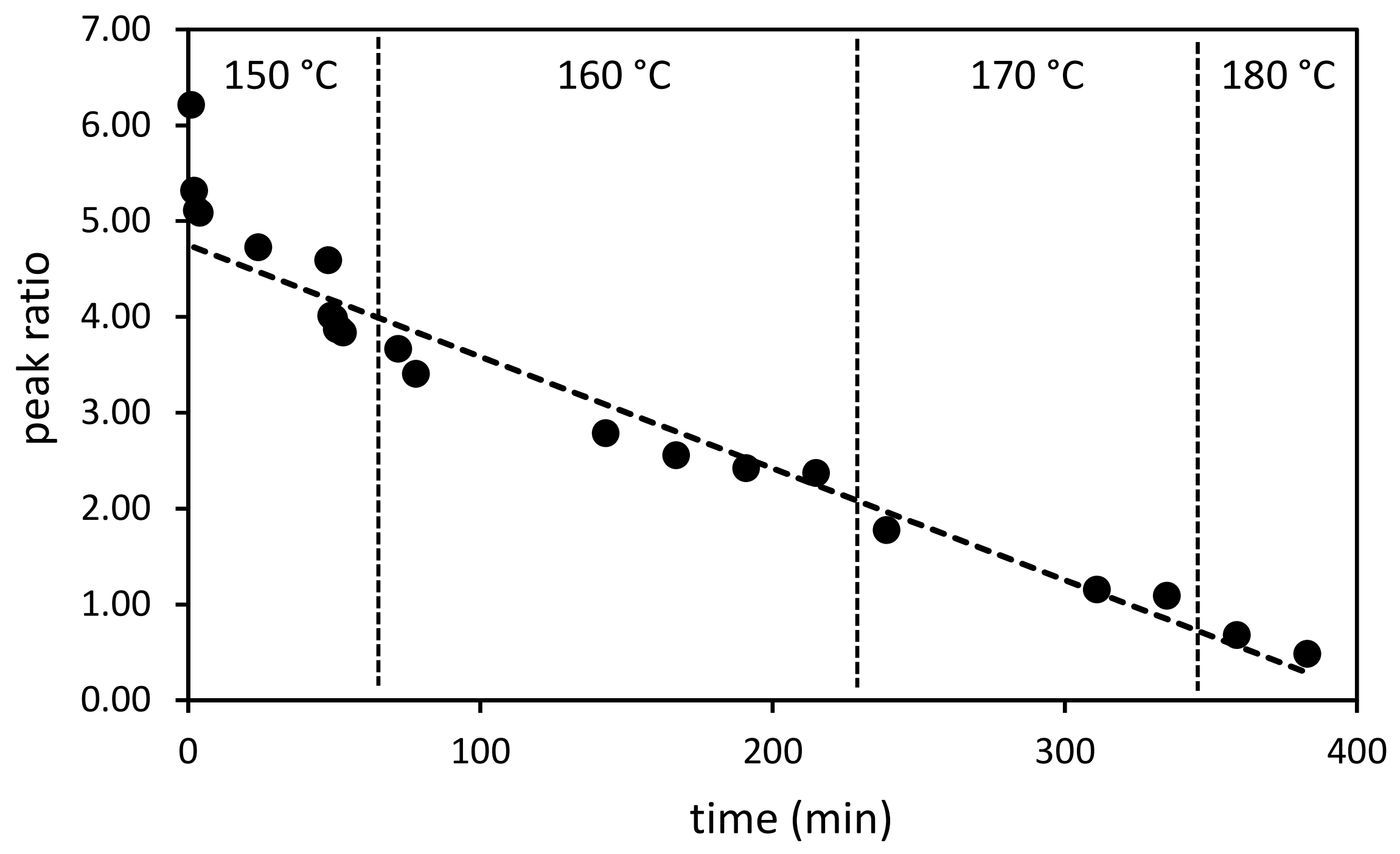

